\title{
A Survey on Farmland Crop Information Acquisition
}

\author{
Danqin Yi and Haiyan Ji \\ College of Information and Electrical Engineering, \\ China Agricultural University, Beijing 100083, China \\ zita_zone@163.com, instru@cau.edu.cn
}

\begin{abstract}
The farmland crop information is the important foundation of developing fine agricultural practice. Crop information acquisition technologies have become the most effective means to increasing crop production and improving crop quality. In this paper, on the basis of introducing the characteristics of farmland crop data, different farmland crop information acquisition methods are surveyed in detail, sections need to be improved of these methods and related core technologies will be discussed. At last, this paper gives a table about crop information acquisition technology and sensing instrument systems applied in different levels (individual level, area level and wide-area level).
\end{abstract}

Keywords: precision agriculture (PA), crop information, information acquisition.

\section{Introduction}

All Food is the paramount necessity of human beings, and the essential material basis for any country on the way of development. China is a great agricultural country with large population, limited soil resources and traditional manual farming methods. With all these challenges, precision agriculture (PA) technologies have been used to improve field practices in crop production these years. PA provides a way to optimize agricultural production inputs, such as irrigation, fertilizing and spraying, based on farmland soil, environment and crop information at individual areas within a field, rather than applying uniform inputs across the entire field. In this way people can obtain not only the best economic benefits but also the ecological benefits.

The three main components involved in PA are information acquisition, data interpretation, and variable-rate application. The PA is an information-based technology. Only spatial information on field conditions as well as inputs and outputs of the field are accurately collected, can PA be successful [1]. The technology of farmland information acquisition directly affects the degree of agricultural informatization and the accuracy of agricultural production's decisions. How to get field soil, environment and crop information conveniently and quickly is the critical issue throughout the entire process of PA. Yet conventional acquisition method of farmland information, which mainly including traditional information retrieval methods and chemical diagnostic methods have many limitations. As to be known, appearance analysis method has strong subjectivity and poor accuracy; chemical

D. Li and Y. Chen (Eds.): CCTA 2013, Part I, IFIP AICT 419, pp. 206-214, 2014.

(C) IFIP International Federation for Information Processing 2014 
diagnosis is based on laboratory analysis of crop organizations, generally requires analyzing samples of crop, costs a lot of time, manpower and material resources [2]. The PA requires fast, real-time and positioning measurement. As the traditional crop information acquisition methods cannot meet the requirement of variable fertilization, we need to develop new methods, especially the technical method and sensing equipment can be used for fast acquisition of farmland information must be developed to meet the need of PA research and practice.

Farmland information can be divided into three parts: soil information, environment information, and crop information [3]. Soil information, including soil moisture, $\mathrm{pH}$, organic matter content, conductivity, soil nutrients, and soil tillage resistance and etc. is the one of the main object of studying farmland information. Farmland environment information includes air temperature, humidity, light intensity, crop pests, and etc. Crop information includes crop growth information (such as canopy structure, leaf area index, plant height, etc.), crop nutrition information (including chlorophyll content, crop water status, nitrogen, phosphorus, potassium etc.) and some other information. Crop information is the most important index used in regulating plant growth, diagnosing crop nutrient deficiency, and predicting crop yields. All these information can make a contribution to agricultural land management and decision-making. High production, high-efficiency and modernizing agriculture can't become true without the help of all kinds of information.

In this paper, on the basis of introducing the characteristics of farmland data, different farmland crop information acquisition methods and related core technologies will be surveyed and discussed.

\section{Characteristic of Farmland Crop Information}

It is extremely important to instruct the agricultural production by knowing the crop it self's information. The farmland system is a very complicated ecology system, involves different kinds of factors. Even the crop itself is a complicated system. The collecting of crop data usually incurs the substantial costs and technologies [4]. To understand the characteristic of crop information fully is very necessary. There are the characteristic of farmland crop information. A) Spatiality. The production of crop is associated with spatial factors. Every farmland has its own geographic location and boundaries. Spatial data is usually used in generating different maps as coordinates. B) Complexity. Any agricultural system has huge factors include not only directly related factors but also indirectly related factors. Each factor contains its sub-factors. Farmland crop data can be collected from multiple sources such as onboard sensors, handheld devices, remote sensing, satellite, history material, etc. Categories of data are diverse, including text, number, image, sound, video, etc. C) Dynamics. All the information is changing all the time according to the time and space [5]. In-time acquisition of data is vital for PA. After all, all these factors increase the difficulty of getting agricultural crop data. People need to master high-tech and stable measurements or means to shield interference and obtain accurate data. 


\section{Crop Information Acquisition Methods}

Crop information includes crop growth information, crop nutrition information, and some other information.

\subsection{Crop Growth Information}

Ground observation, remote sensing monitoring and model simulation are the main methods of monitor crop growth and development information. The leaf area index (LAI), canopy characterization, canopy structure, plant height and other growth factors are the main target be measured to monitor crop-growing status [6].

Remote sensing is becoming more and more popular for its unique advantages. M. Susan Moran et al. [7] successfully used aerial and satellite remote sensing data to inverse normalized difference vegetation index (NDVI) values, which can be used for diagnosis, estimation and production forecasting of large area crops [8]. Huang Jingfeng et al. [9] established Rice-SRS model to estimate the yield of rice with spectral normalized vegetation index obtained by NOAA/AVHRR satellite. Peng Xiao et al. [10] used the TM remote sensing image to obtain NDVI and inverse the LAI of rice. On the basis of domestic airborne imaging spectrum data and the spectral response of the synchronous sampling data, Yang Minhua et al [11] established wheat canopy physical and chemical parameters estimation model and realized the inversion of wheat canopy physical and chemical parameters through aerial hyper spectral remote sensing.

Infrared beam, ultrasonic, microelectrode constant current source technology and some other technologies can be used to monitor and analyze growing crops directly. Shimizu H et al. [12] used machine vision technology to non-contact measure threedimensional growth information of crops. Zhao Chunjiang et al. [13] developed an instrument to inverse LAI, vegetation cover degree, biomass index to assess crop condition. This instrument uses the near-infrared and red characteristic bands, and detects the incident light and the reflected light of vegetation to get the NDVI (normalized difference vegetation index) values. Aziz S A et al. [14] studied ultrasonic sensing technology. They used it as one approach for corn plant canopy characterization. Lan Yubin et al. [15] developed a ground-based Multi-sensor fusion integration system, including a crop height sensor, a crop canopy analyzer for LAI, a NDVI sensor, a multispectral camera, and a hyper spectroradiometer to measure realtime crop conditions involve NDVI, biomass, crop canopy structure, and crop height. $\mathrm{Qu}$ Yonghua et al. [16] developed an automatic system designed on the basis of wireless sensors network (WSN) to collect crop structure parameters, like LAI and average leaf angle (ALA).

Plant height is an important parameter to be considered for management decision making. Plant height is a sensitive indicator to show plant health status and calculate yield potential in optimizing field inputs. Sui Ruixiu et al. [17] used ultrasonic sensors to develop a microcomputer-based measurement system to allow in-situ, nondestructive measurement for the morphological characteristics of bush-type plants. Searcy S W et al. [18] developed and field-tested an infrared beam sensor mounted on 
a mechanical arm, using a "light curtain" for the cotton plant real-time height measurement. Tumbo S D et al. [19] successfully used ultrasonic sensors in the measurement of citrus tree volume. Ehsani M R et al. [20] investigated a laser-based sensor which can realize real-time estimate of plant volume. The sensor also performed well in measuring the biomass and LAI of a plant after being calibrated. Jones C L et al. [21] used ultrasonic distance sensing to realize plant height data collection, and estimated plant biomass using the product of top-view surface area of the plant. Sui Ruixiu et al. [22] used an ultrasonic sensor installed on a field vehicle such as a sprayer to scan the plant canopy and determine plant height in real time in situ. A plant height map was generated with the collected data by the sensor.

\subsection{Crop Nutrition Information}

For crop chlorophyll content nondestructive testing, MINOLTA company in Japan has produced a kind of Chlorophyll meter, which emit red light (about 650nm) and near infrared light (about 940nm) by the light emitting diode to the receiver through the leaf samples. The receiver receives the signals and transfers them into digital signals that will be used by the microprocessor to calculate the SPAD value. Yao Jiansong et al. [23] used visible-near infrared spectroscopy techniques to nondestructive test rape leaf chlorophyll content information. Liu Fei et al. [24] used visible/near infrared spectrum technology, quickly and accurately detected cucumber leaf SPAD value, which is helpful to the development of testing equipment.

Nitrogen is one of the most important factors that have a high impact on the production of crops. The main methods of monitoring nitrogen are remote sensing imaging, machine vision technology, spectrum analysis technology, Multi-spectral and hyperspectral imaging technology [25]. The remote sensing based crop nitrogen nutrition diagnosis, most people use remote sensing to inverse nitrogen concentration, nitrogen accumulation and other parameters which can determine crop nitrogen nutritional status [26]. He Yong et al. [2] developed a portable plant nutrients lossless tester to determine plant chlorophyll, water, nitrogen content quickly, non-destructive, and simultaneously. This instrument has a GPS and a wireless data transmission function. Combined with GIS software management system, large-scale crop nutrient content distribution map can be developed. Feng lei et al. [27] put the rape as the research object, used computer multi-spectral imaging technology for rapidly, accurately and non-destructive nitrogen diagnosis.

Crop water information collection is the basis of precision irrigation decisionmaking. It is a key for continuously, quickly, and precisely information collecting. Crop water information is helpful to develop advanced and reliable monitoring equipment. Crop water status information collection technologies of crop individual include infrared temperature method, leaf water potential, spectral method, etc. Regional crop water status information is mainly obtained through remote sensing methods, including thermal infrared remote sensing and microwave remote sensing methods [28]. Ji Haiyan et al. [29] used near-infrared spectroscopy, developed a living plant leaves water testing instrument which adopts ultra-low-power microprocessor MSP430 and new type of optical frequency conversion chip TSL230, 
enabled field site fast non-destructive testing of crop leaf water content. Li Dongsheng et al. [30] developed the leaf temperature-measuring instrument, using infrared thermometry to measure leaf temperature to estimate leaf moisture state.

Canopy temperature relative to ambient air temperature is often used to assess plant stress caused by moisture deficit or high temperature [31] [32]. Continuous measurement of plant canopy temperature is useful in both research and agricultural production. James R. Mahana et al. [33] studied a low-cost infrared sensor based wireless temperature monitoring system, assessed the system's reliability and stability, and verified the feasibility of low-cost infrared temperature measurement system. O'Shaughnessy et al. [34] developed a wireless sensor system comprised mainly of infrared thermometer thermocouples located on a center pivot lateral and in the field below to monitor crop canopy temperatures. Daniel K. Fisher et al. [35] developed and constructed a low-cost microcontroller based system to monitor the temperature and the water status of crop. The system can realize automatic measurement of canopy temperature, soil temperature, air temperature, and soil moisture status in field. It includes a digital infrared temperature sensor, choose MLX90614 (Melexis. Concord. NH) infrared temperature module to get the plant canopy (leaf) temperature. The precision of the system is 0.3 degrees Celsius by experiments.

\subsection{Others}

Crop yield is the result of many factors, is the important data of the variable assignment management [36]. Commercialized grain yield monitor systems are mainly the AFS (advanced farming system) system (CASE IH Corporation, U.S.), the FieldStar system (AGCO Corporation, British), the Greenstar system (JohnDeree Corporation, USA), the PF (precision farming) system (AgLeader Corporation, USA), the production monitoring system of RDS, etc. All these systems are equipped with GPS positioning system, can automatically monitor crop production and make a crop yield map. Cereal production yield monitor sensor is the core of these systems, including the photoelectric volumetric flow sensor, the $\gamma$-ray impulse flow sensor and the impulse type flow sensor [3]. Some portable information collection and transmission systems have combined with GPS, GPRS or Zigbee technology, were built to obtain pictures, sounds, numbers, GPS information or any other data of field crops [37-40].

\section{Discussions and Conclusions}

\subsection{Crop Information Acquisition}

There have been many associated reports about rapid detection methods and instruments of the nitrogen content, chlorophyll content, and moisture content. And there are also some reports about detection methods of phosphorus and potassium content. But the report about crop trace information is less. This is mainly because the 
main crop trace information is metal elements based, and their content is low. The ordinary sensing technology still not meets the requirements, and the use of spectrum and spectral imaging technologies doesn't directly react to metal element information.

\subsection{The Core Technologies}

\section{- GPS}

Farmland location information, which including latitude, longitude, shape and size of farmland, is mainly obtained through GPS (global positioning system). GPS technology is currently widely used in agricultural crop information acquisition systems, can be combined with crop information to make crop distribution map.

- Multi-sensor information fusion technology

Multi-sensor information fusion technology is a comprehensive automated information processing technology [41]. The use of real-time multi-sensor information fusion technology has become a new hot spot to simultaneously measure multiple parameters [42].

- Wireless communication technology

Wireless communication can be classified as long-distance communication (GSM, GPRS, etc.) and short-range communications (Bluetooth, Zigbee, RFID, etc.) [43]. GSM and GPRS, based on mobile communication network, can achieve remote agricultural information acquisition and monitoring. Wireless sensor networks, which has developed in recent years, integrate sensor technology, embedded technology, modern networking and wireless communication technology. It can achieve real-time data transmission via low-power short-range wireless communications technology (such as Wifi, Bluetooth, Zigbee, RFID, etc.). Farmland information self-organizing wireless sensor network system can be established.

- Multispectral / Hyperspectral imaging technology

As spectroscopic technique is easily affected by soil background, environment, crop canopy structure, the obtained spectrum signal is not able to completely react crops truthful information. Multispectral and hyperspectral imaging technology can make up for these shortcomings [2]. The researches about multispectral and hyperspectral imaging technology used in the crop phosphorus, potassium, and trace information are less. But there are already reports about multi-spectral imaging technology applied to detect the moisture content of crop leaves [44]. We had better establish the quantitative relationship between the spectral characteristics and crop growth/nutrition information and develop crop information equipment.

\subsection{Conclusion}

PA is an information-based technology. PA can use crop information in the farmland to control the arrangement of production inputs, maximize crop profit, and minimize environmental impact. Information acquisition and processing plays a very important role in PA. As shown in table 1, after understanding crop information acquisition methods, combined with the current situation and development trend, a structure about crop information acquisition technology and sensing instrument system is listed. 
Table 1. Crop information acquisition technology and sensing instrument system structure

\begin{tabular}{|c|c|c|c|}
\hline Level & Features of Object & $\begin{array}{l}\text { applied technology } \\
\text { innovation }\end{array}$ & $\begin{array}{l}\text { Application } \\
\text { characteristics }\end{array}$ \\
\hline Individual & $\begin{array}{l}\text {-Individual information } \\
\text { for crops } \\
\text {-Farmland } \\
\text { environmental factors } \\
\text { interference }\end{array}$ & $\begin{array}{l}\text {-Non-contact } \\
\text { measurement } \\
\cdot \text { The embedded system }\end{array}$ & $\begin{array}{l}\text {-Quick and non- } \\
\text { destructive detective } \\
\cdot \text { Portable } \\
\cdot \text { Handheld }\end{array}$ \\
\hline Area & $\begin{array}{l}\text {-Complicated } \\
\text { environment } \\
\text {-Need location } \\
\text { information }\end{array}$ & $\begin{array}{l}\text {-Spectroscopy } \\
\text {-Multi-spectral imaging } \\
\text { technology } \\
\text {-GPS }\end{array}$ & -Vehicular \\
\hline Wide-area & $\begin{array}{l}\text { Spatiality } \\
\text {-Irregular shape of } \\
\text { farmland }\end{array}$ & $\begin{array}{l}\cdot \text { Remote sensing } \\
\text { technology } \\
\text {-Wireless sensor } \\
\text { network }\end{array}$ & -Teletransmission \\
\hline
\end{tabular}

\section{References}

1. Wang, M.: Development of Precision Agriculture and Innovation of Engineering Technologies. Transactions of the Chinese Society of Agricultural Engineering 1 (1999)

2. He, Y., Zhao, C., Wu, D., Nie, P., Feng, L.: Fast detection technique and sensor instruments for crop-environment information: A review. Scientia Sinica, Informationis S1 (2010)

3. Wang, F., Zhang, S.: Research Progress of the Farming Information Collections Key Technologies on Precision Agriculture. Transactions of the Chinese Society for Agricultural Machinery 5 (2008)

4. Liu, X., Nelson, M., Ibrahim, M.: The Value of Information in Precision Farming. Paper of the Southern Agricultural Economics Association Annual Meeting (2008)

5. Duan, Y., Niu, X.: Research on Farmland Information Acquisition System Based on IoT. Advanced Materials Research (Volumes 532 - 533) (2012)

6. Zhang, G., Chen, H., Zhou, G.F., Ge, G.M.: A Survey on Crop growth dynamic monitoring technology. Chinese Meteorological Society 9 (2010)

7. A RADARSAT-2 Quad-Polarized Time Series for Monitoring Crop and Soil Conditions in Barrax, Spain. IEEE Transactions on Geoscience and Remote Sensing 50(4) (2012)

8. He, D., He, Y., Li, M., Hong, T.: Research Progress of Information Science-related Problems in Precision Agriculture. China Academic Journal Electronic Publishing House 01, 10-16 (2011)

9. Huang, J., Tang, S., Ousama, A., et al.: Rice yield estimation using remote sensing and simulation model. J. Zhejiang U Sci. A 3, 1862-1775 (2002)

10. Peng, X., Zhang, S.: Research on Rice Growth Status Based on NDVI and LAI. Remote Sensing Technology and Application 1 (2002)

11. Yang, M., Liu, L., Liu, T., et al.: Research on a Method to Retrieve Biophysical and Biochemical Parameters of Wheat Canopy with Hyperspectral Remote Sensing. Geodaetica Et Cartographic Sinica 4 (2002)

12. Shimizu, H., Heins, R.D.: Computer vision based system for plant growth analysis. Trans. ASAE 38, 958-964 (1995) 
13. Zhao, C., Liu, L., Zhou, H., et al.: Development and application of a novel NDVI instrument. Optical Technique 30(3), 324-326, 329 (2004)

14. Aziz, S.A., Steward, B.L., Birrell, S.J., Shrestha, D.S., Kaspar, T.C.: Ultrasonic sensing for corn plant canopy characterization. ASAE Paper No. 041120. St. Joseph, Mich.: ASAE (2004)

15. Lan, Y., Zhang, H., Lacey, R., Hoffmann, W.C., Wu, W.: Development of an Integrated Sensor and Instrumentation System for Measuring Crop Conditions. Agricultural Engineering International: CIGR Journal (2009)

16. Qu, Y., Wang, J., Dong, J., et al.: Design and experiment of crop structural parameters automatic measurement system. Transactions of the CSAE 28(2), 160-165 (2012)

17. Sui, R., Wilkerson, J.B., Wilhelm, L.R., Tompkins, F.D.: A microcomputer-based morphometer for bush-type plants. Computer and Electronics in Agriculture 4, 43-58 (1989)

18. Searcy, S.W., Beck, A.D.: Real time assessment of cotton plant height. In: Proceedings of Fifth International Conference on Precision Agriculture (CD), Bloomington, MN, USA (2000)

19. Tumbo, S.D., Salyani, M., Whitney, J.D., Wheaton, T.A., Miller, W.M.: Investigation of laser and ultrasonic ranging sensors for measurements of citrus canopy volume. Applied Engineering in Agriculture 18(3), 367-372 (2002)

20. Ehsani, M.R., Lang, L.: A sensor for rapid estimation of plant biomass. In: Proc. the 6th Intl. Conf. on Precision Agri., Bloomington, MN, pp. 14-17 (July 2002)

21. Jones, C.L., Maness, N.O., Stone, M.L., Jayasekara, R.: Sonar and digital imagery for estimating crop biomass. ASAE Paper No. 043061. St. Joseph, Mich.: ASAE (2004)

22. Sui, R., Alex Thomasson, J., Ge, Y.: Development of Sensor Systems for Precision Agriculture in Cotton. Int. J. Agric. \& Biol. Eng. 5(4), 1-14 (2012)

23. Yao, J., Yang, H., He, Y.: Nondestructive Detection of Rape Leaf Chlorophyll Level Based on Vis/NIR spectroscopy. Journal of Zhejiang University (Agriculture and Life Sciences) 4 (2009)

24. Liu, F., Wang, L., He, Y., Bao, Y.: Detection of SPAD Value of Cucumber Leaves Based on Visible/near Infrared Spectroscopy Technique. Journal of Infrared and Millimeter Waves 4 (2009)

25. Li, G., Zhu, L., Li, J.: Present Status of Research and Application of Non-destructive Measurement of Nitrogen Nutrition Diagnosis. Heilongjiang Agricultural Sciences 4, 127-129 (2008)

26. Chen, P., Sun, J., Wang, J., et al.: Using remote sensing technology for crop nitrogen diagnosis: status and trends. Scientia Sinica (Informationis), S1 (2010)

27. Feng, L., Fang, H., Zhou, W., et al.: Nitrogen Stress Measurement of Canola Based on Multi-Spectral Charged Coupled Device Imaging Sensor. Spectroscopy and Spectral Analysis 9, 1749-1752 (2006)

28. Duan, A., Meng, Z.: Present Situation of Techniques and Equipments of Monitoring Crop Water Status. Review of China Agricultural Science and Technology 9(1), 6-14 (2007)

29. Hou, R., Ji, H., Rao, Z., et al.: Water detection instrument design for living leaves based on near infrared spectroscopy. Transactions of the Chinese Society of Agricultural Engineering S2 (2009)

30. Li, D., Guo, L., Guo, C., et al.: Development of leaf temperature measuring instrument and its application in plant leaf parameter measurement. Transactions of the Chinese Society of Agricultural Engineering (Transactions of the CSAE) 28(5), 139-144 (2012) 
31. González-Dugo, M.P., Moran, M.S., Mateos, L., Bryant, R.: Canopy temperature variability as an indicator of crop water stress severity. Irrigation Science 24, 233-240 (2006)

32. Reynolds, M.P., Pierre, C.S., Saad, A.S.I., Vargas, M., Condon, A.G.: Evaluating potential genetic gains in wheat associated with stress-adaptive trait expression in elite genetic resources under drought and heat stress. Crop Science 47, 172-189 (2007)

33. Mahana, J.R., Conatyb.c, W., Neilsenc, J., Payton, P., Cox, S.B.: Field performance in agricultural settings of a wireless temperature monitoring system based on a low-cost infrared sensor. Computers and Electronics in Agriculture 71, 176-181 (2010)

34. O'Shaughnessy, S.A., Evett, S.R.: Developing Wireless Sensor Networks for Monitoring Crop Canopy Temperature Using a Moving Sprinkler System as a Platform. Applied Engineering in Agriculture 26(2) (2010)

35. Fisher, D.K., Kebede, H.: A low-cost microcontroller-based system to monitor crop temperature and water status. Computers and Electronics in Agriculture 74, 168-173 (2010)

36. Thylen, L., Murphy, D.P.L.: The control of errors in momentary yield data from combine harvesters. Journal of Agriculture Engineering Research 64(4), 271-278 (1996)

37. Kuang, Y., Xiao, M.: The Field Information Collection Apparatus. Journal of Agricultural Mechanization Research 8 (2010)

38. Cai, Y., Liu, G.: Development of portable system of field information collection and wireless transmission. In: Proceedings of Commemorate the Chinese Society of Agricultural Engineering was established 30 anniversary of Chinese Society of Agricultural Engineering 2009 Annual Conference, CSAE 2009 (2009)

39. Xu, X., Li, Z., Zhang, J.: The Design of Portable Cropland Information Collection Equipment Base on GPRS and GPS Technology. Journal of Agricultural Mechanization Research 8 (2008)

40. Zheng, X., et al.: Study on Design of Farmland Information Acquisition and Transmission System Based on ZigBee. Journal of Anhui Agricultural Sciences 6 (2003)

41. Li, X., Wang, W., Lei, T., et al.: Prospects of the application of multi-sensor information fusion techniques in agricultural engineering. Transactions of the CSAE 19(3), 10-12 (2003)

42. Han, C., Zhu, H.: Multi-sensor information fusion and automation. Acta Automatica Sinica (S1), 117-124 (2002)

43. Yang, W., Li, M., Wang, X.: Status quo and progress of data transmission and communication technology in field information acquisition. Transactions of the CSAE 24(5), 297-301 (2008)

44. Ramalingam, N., Ling, P.P., Derksen, B.C.: Background reflectance compensation and its effect on multispectral leaf surface moisture assessment. Trans. ASAE 48, 375-383 (2005) 